\title{
INSERÇÃO DA EDUCAÇÃO AMBIENTAL NOS ESPAÇOS ESCOLARES: ANÁLISE DA PRÁTICA DO PROFESSOR DE CIÊNCIAS NO SEXTO ANO DO ENSINO FUN- DAMENTAL
}

\author{
THE INSERTION OF ENVIRONMENTAL EDUCATION IN SCHOOL SPACES: ANALYSIS OF THE SCI- \\ ENCE TEACHER PRACTICE IN THE SIXTH GRADE OF ELEMENTARY SCHOOL
}

\section{INSERCIÓN DE LA EDUCACIÓN AMBIENTAL EN ESPACIOS ESCOLARES: ANÁLISIS DE LA PRÁCTI- CA DOCENTE DE CIENCIAS EN EL SEXTO GRADO DE EDUCACIÓN PRIMARIA}

\author{
Waldelice Oliveira Almeida \\ Mestranda do Programa de Pós-graduação em Gestão do Ensino na Educação Básica. \\ Professora da rede estadual e Municipal de Ensino - SEDUC/SEMED/Maranhão. \\ E-mail: waldeliceoalmeida2@gmail.com \\ Amanda Marcos Coelho \\ Mestranda do Programa de Pós-graduação em Gestão do Ensino na Educação Básica. \\ Professora da rede particular de Ensino Superior no estado do Maranhão. \\ E-mail: amanda_amandamc@hotmail.com \\ Clara Virgínia Vieira Carvalho Oliveira Marques \\ Doutora em Química - UFSC. Profa. Adjunta III da Universidade Federal do Maranhão \\ E-mail: clarabrasil10@gmail.com
}

\begin{abstract}
RESUMO
No que se refere ao ensino de Ciências, os atuais paradigmas educacionais apontam para a necessidade de promoção de um ensino voltado para a cidadania, estimulando a construção de valores e atitudes nos sujeitos em formação, através da reflexão crítica e participativa na sociedade, atentado para os saberes científicos a serem adquiridos e empregados de forma significativa. No tocante ao papel de educador, entende-se como importante estimular práticas consonantes com os ideais ecológicas, uma vez que esse viés proporciona desenvolver atitudes e comportamentos ecologicamente aceitos orientandos as escolhas no sentido da proteção do meio ambiente. Dessa forma, a presente artigo apresenta um recorte de pesquisa de mestrado onde se abordou uma discussão que diz respeito à relação entre ensino de Ciências e Educação Ambiental para a formação dos sujeitos ecológicos a partir do Ensino Fundamental, na ótica da prática docente. O estudo utiliza a perspectiva de pesquisa qualitativa, cuja coleta de dados se deu em seis escolas da rede municipal do Ensino Fundamental de São Luís /Maranhão. Os sujeitos da pesquisa foram professores de Ciências que responderam a questionários e entrevistas com o objetivo de investigar o conceito e a prática da Educação Ambiental, a fim de caracterizar as ações pedagógicas de cunho ambiental desenvolvida por eles. Os resultados alcançados apontaram que há uma diversidade de entendimento sobre Educação Ambiental bem como diversidade de ações pedagógicas, mas há uma compreensão comum sobre a importância de levar as questões ambientais para os espaços escolares ainda que, de fato, não sejam efetivadas.
\end{abstract}

Palavras-chave: Educação Ambiental; Sujeito ecológico; Professores de ciências

\section{ABSTRACT}

Regarding science teaching, current educational paradigms point to the need to promote citizenship education, stimulating the construction of values and attitudes in the subjects in formation, through critical and participatory reflection in society, an attempt to the scientific knowledge to be acquired and employed significantly. Concerning the role of the educator, it is important to encourage practices that are in line with ecological ideals, since this bias provides the development of ecologically accepted attitudes and behaviors, guiding the choices towards the protection of the environment. Thus, this article presents an excerpt of a master's research, which addressed a discussion regarding the relationship between science teaching and 
Environmental Education for the formation of ecological subjects from the elementary school on, from the perspective of teaching practice. The study uses the perspective of qualitative research whose data collection took place in six elementary schools in São Luís / Maranhão. The subjects of the research were Science teachers who answered questionnaires and interviews applied in order to investigate the concept and the practice of Environmental Education, in order to characterize the pedagogical actions of environmental nature developed by them. The results showed that there is a diversity of understanding about Environmental Education as well as diversity of pedagogical actions, but there is a common understanding about the importance of bringing environmental issues to school spaces even if they are not actually implemented.

Keywords: Environmental Education; Eco-Friendly; Science Teachers

\section{RESUMEN}

Con respecto a la enseñanza de las ciencias, los paradigmas educativos actuales apuntan a la necesidad de promover la educación para la ciudadanía, que estimule la construcción de valores y actitudes en los sujetos en formación, a través de reflexión crítica y participativa en la sociedad. Esa educación debe estar dirigida hacia el conocimiento científico a ser adquirido y empleado significativamente. En cuanto al papel del educador, es importante fomentar prácticas que estén en línea con los ideales ecológicos, ya que este sesgo proporciona el desarrollo de actitudes y comportamientos ecológicamente aceptados, y orienta las elecciones hacia la protección del medio ambiente. Por lo tanto, este artículo presenta un aspecto de la investigación realizada en la maestría, que abordó la relación entre la enseñanza de las ciencias y la educación ambiental, con el fin de formar sujetos ecológicos a partir de la educación inicial, desde la perspectiva de la práctica docente. El estudio asume la perspectiva de la investigación cualitativa cuya recolección de datos se llevó a cabo en seis escuelas de la red escolar municipal de São Luís / Maranhão. Los sujetos de la investigación fueron maestros de ciencias que respondieron a cuestionarios y entrevistas, elaborados para investigar el concepto y la práctica de la Educación Ambiental y para caracterizar las acciones pedagógicas de naturaleza ambiental desarrolladas por ellos. Los resultados mostraron que hay muchas concepciones sobre la Educación Ambiental, así como también una diversidad de acciones pedagógicas, pero existe una posición compartida acerca de la importancia de llevar los problemas ambientales a los espacios escolares, incluso si no se implementan en la práctica.

Palabras-clave: Educación Ambiental; Sujeto ecológico; Maestros de Ciencias

\section{INTRODUÇÃO}

A Educação Ambiental é uma atividade educativa que pode ser desenvolvida em ambientes formais e não formais de ensino. Historicamente, a EA surgiu de movimentos ambientalistas que questionavam os impactos ambientais promovidos por mudanças no modo de produção de bens e serviços. Essas mudanças foram trazidas pela Revolução industrial no Século XVIII, o que produziu muito conforto ao homem, mas também significativos desequilíbrios ambientais (SILVA, 2007).

A expressão Educação Ambiental originou-se do termo Enviroment Education e segundo Dias (2004), foi usada pela primeira vez na Conferência das Nações Unidas sobre o Meio Ambiente realizada em 1972, na cidade de Estocolmo, ficando consagrada como 
“Conferência de Estocolmo”, além de abrir caminho para outras conferências que se estabeleceram por estimular o debate e advertir à sociedade sobre a crise ambiental, influenciando na elaboração de leis que visavam à regulamentação e normatização da Educação Ambiental para torná-la efetiva, no espaço educacional em todos os níveis e modalidades e na comunidade como um todo. Dessa forma, podemos afirmar que a Educação Ambiental se manifestou, como ação alternativa para envolver a sociedade na resolução dos problemas ambientais. Diante dessa realidade, faz-se necessário a discussão acerca das consequências do formato de produção e da aplicação dos conhecimentos científicos no Meio Ambiente, assim como os impactos políticos e sociais decorrentes deles. Essa discussão deveria ocorrer tanto na sala de aula quanto no âmbito social (BRASIL, 1997).

Nas últimas décadas, houve um recrudescimento dos problemas ambientais que ameaçam a sobrevivência do planeta (RAMOS, 2001; TOZONI-REIS; CAMPOS, 2014; SENA; BONOTTO, 2012). É nesse cenário que a inserção da Educação Ambiental se faz mais necessária, sobretudo pela possibilidade da formação de uma cidadania ecológica, forjada pelo conhecimento científico e ecológico, além de valores que fundamentam a compreensão dos problemas ambientais e orientam a tomada de decisões quanto ao seu enfrentamento (CARVALHO, 2012).

Nessa perspectiva, a temática ambiental passa a ser tratada nos Parâmetros Curriculares Nacionais - PCNs (BRASIL, 1997) - atualmente substituídos pela Base Nacional Comum Curricular -BNCC (BRASIL, 2017) - como tema transversal e como tal, ampliada para todas as áreas do conhecimento. Contudo, as questões ambientais, embora universais, ainda são destinadas aos componentes curriculares de Ciências e Geografia.

No que tange ao ensino de Ciências, a inserção da Educação Ambiental está relacionada à postura pessoal do professor, assim se ele tem atitudes ecológicas, demonstra então preocupação com a preservação do meio ambiente (SATO; CARVALHO, 2005; KRASILCHIK; MARANDINO, 2007; CARVALHO, 2012;). O professor sujeito ecológico tende a levar essa preocupação para suas aulas de ciências, sendo exemplo para os estudantes. Isso estimulará a formação de uma cidadania ecológica conjunta e o estudante será instigado a pensar e tentar resolver os problemas ambientais que se apresentarem na sua escola e 
comunidade (LIMA, 2009; SENA; BONOTTO, 2012; CARVALHO, 2012). O processo de subjetivação do ideário ecológico, segundo Carvalho (2013), por parte do professor tem mais relevância, ou seja, para desenvolver atividades de Educação Ambiental o professor precisa ter dentro de si o ideário ecológico que fundamentará suas ações e sensibilizará os estudantes a exercerem a cidadania ecológica.

Diante do exposto, e, visando proporcionar uma visão mais ampla da problemática ambiental, é que se construiu a presente pesquisa. Buscou-se conhecer de que forma a prática docente contribui para a inserção da temática ambiental nas aulas de Ciências, precisamente no Sexto Ano do Ensino Fundamental em escolas da Rede Pública Municipal de São Luís.

\section{Percurso Metodológico}

O texto que ora se apresenta é um recorte de uma pesquisa de mestrado que tem como objetivo investigar a inserção da Educação Ambiental nas aulas de Ciências do sexto ano do Ensino Fundamental. O trabalho estruturou-se na perspectiva de uma pesquisa qualitativa que pressupõe o contato direto do pesquisador com o ambiente e a situação que está sendo investigada (LUDKE, ANDRÉ, 1986). Para a análise qualitativa dos dados coletados recorreu-se a Izquierdo, Sanmarti e Espinet (1999), que defendem a necessidade de um processo sistemático de seleção, categorização, comparação, síntese e interpretação dos dados para a explicação do fenômeno estudado. Corbin e Strauss (2008) entendem que a análise qualitativa se configura como a busca de uma teoria fundamentada por meio da codificação dos dados, assim como dos principais elementos relatados pelos dados obtidos. Os autores citados explicam que embora ocorra a teorização, essa caracteriza-se como uma ação, uma concepção e formulação de ideias em um esquema explanatório e sistemático.

A pesquisa foi realizada em escolas da rede municipal de ensino de São Luís, que ofertam o Ensino Fundamental/2 ${ }^{\mathrm{a}}$ Etapa. A organização das escolas municipais no referido município se faz por nucleação de instituições escolares por proximidades de bairros. Essa 
organização tem por objetivo facilitar o acompanhamento das escolas pela equipe pedagógica da Secretaria de Educação. O município de São Luís tem cinco núcleos, e o escolhido foi o Núcleo Anil, constituído por seis escolas. O motivo da escolha desse núcleo deve-se à existência de problemas ambientais que se iniciaram pela instalação de uma fábrica de tecidos, A Fábrica de Tecidos Rio Anil, em 1893 nas margens do Rio Anil e fechada em 1960 (FEITOSA, 2016).

O conjunto de sujeitos dessa pesquisa foi configurado por seis professores de Ciências do sexto ano do ensino fundamental regular, lotados nas unidades de ensino que compõem o núcleo escolhido. Os planos anuais dos professores foram analisados com o intuito de identificar as atividades de Educação Ambiental que são idealizadas e desenvolvidas.

Nesta pesquisa, utilizou-se como instrumento de coleta de dados questionários e entrevistas aplicados aos professores de Ciências. Procedeu-se também a análise documental dos planos anuais elaborados pelos professores pesquisados. O tratamento dos dados se deu por análise do conteúdo, suscitando categorização das unidades de significados (US) mais recorrentes identificadas nas falas dos professores e organizadas em blocos de discussões (BARDIN, 2010; BOGDAN,1994; BIKLEN, 2004; MARQUES, 2010).

\section{Resultados e Discussões}

A análise dos dados obtidos foi organizada em duas etapas: seção I: Análise dos planos anuais da disciplina de Ciências e seção II: Análise de conteúdo das entrevistas cedidas pelos professores. A Seção II foi configurada em volta de dois blocos de discussões, denominados respectivamente de bloco I: Concepções gerais sobre Educação Ambiental e de bloco II: Perfil de implementação de atividades de Educação Ambiental. Para o tratamento dos dados da Seção II, utilizou-se a análise das entrevistas, que foi realizada através de análise de conteúdo (BARDIN, 2010). Foram retiradas as unidades de significados (US) ou signos mais recorrentes e em seguida procedeu-se a categorização para posterior organização dos blocos de discussão, formando uma rede sistêmica (BOGDAN; BIKLEN, 2004; MARQUES, 2010). 


\section{Perfil formativo dos professores de Ciências do campo de pesquisa}

Para início da pesquisa, entendeu-se como necessário identificar o perfil formativo em nível de graduação e pós-graduação dos professores que formavam o conjunto de docentes do núcleo de escolas selecionadas. Portanto, foram entrevistados inicialmente todos os professores de Ciências do Núcleo Anil, atuantes no $6^{\circ}$ ao $9^{\circ}$ ano, perfazendo um montante de 16 professores. Dessa forma, no que se refere à formação inicial, dos 16 professores, 50\% são formados em Biologia e atendem ao requisito para exercer o cargo de professor de Ciências, uma vez que são habilitados para exercer o cargo de professor de Ciências de acordo com a Lei de Diretrizes e Bases da Educação Nacional (LDB), Lei 9.394/1996. Porém, um fato que chamou atenção diz respeito a professores com habilitações distantes das Ciências Naturais. Quando o professor não atinge a carga horária de 12 horas de efetiva atividade de sala de aula, ele deve completar essa carga horária, uma política interna da Secretaria Municipal de Educação (SEMED). Essa complementação pode ocorrer em outra escola, na sua disciplina de formação para a qual submeteu-se a concurso público ou em qualquer disciplina, a exemplo dos professores formados em Letras, Geografia e Construção Civil que completam sua carga horária com a disciplina Ciências.

Não foi avaliado o impacto no processo ensino aprendizagem e no desenvolvimento de atividades de Educação Ambiental dessa determinação da Secretaria Municipal de Educação quanto à complementação de carga horária com professores não habilitados para a disciplina Ciências .Isso pode ser objeto de estudo de pesquisas futuras, porém, no que se refere à formação do sujeito ecológico, o processo de subjetivação do ideário ecológico por parte do professor tem mais relevância, segundo Carvalho (2013).Para executar as atividades de EA, o professor precisa ser exemplo e ter dentro de si o ideário ecológico. Se o educador no seu cotidiano tem uma preocupação com a preservação do meio ambiente, ele tenderá a formar uma cidadania ecológica; assim, o estudante se sente estimuladopelo exemplo- a resolver problemas que possam vir a ocorrer sua escola e comunidade.

No que se refere à formação em nível de pós-graduação, $25 \%$ dos professores entrevistados informaram não possuir nenhum curso de pós-graduação. Já o restante possui algum curso desse nível. Os cursos informados são diversificados e estão, em grande parte, relacio- 
nados direta ou indiretamente ao componente curricular Ciências e à Educação Ambiental, como por exemplo: Especialização em Ciências Naturais, Meio Ambiente, Biodiversidade e Conservação, Engenharia Sanitária e Gestão Ambiental, conforme demonstra a tabela 1.

Tabela 1 - Formação superior em nível de graduação e pós-graduação

\begin{tabular}{|c|c|c|}
\hline Graduação & $\%$ & Professores \\
\hline Biologia & $50 \%$ & 8 \\
\hline Física & $12,50 \%$ & 2 \\
\hline Lic. Em Construção Civil & $6,25 \%$ & 1 \\
\hline Geografia & $6,25 \%$ & 1 \\
\hline Letras & $6,25 \%$ & 1 \\
\hline Matemática & $6,25 \%$ & 1 \\
\hline Química & $6,25 \%$ & 1 \\
\hline Química e Biologia & $6,25 \%$ & 1 \\
\hline Pós-graduação & $\%$ & Professores \\
\hline Biodiversidade e Conservação & $6,25 \%$ & 1 \\
\hline Meio ambiente & $12,50 \%$ & 2 \\
\hline Met. de Ens. da Física & $6,25 \%$ & 1 \\
\hline $\begin{array}{c}\text { Especialização (não lembrou o } \\
\text { nome) }\end{array}$ & $6,25 \%$ & 1 \\
\hline Mídias na Educação & $6,25 \%$ & 1 \\
\hline Saúde Pública & $6,25 \%$ & 1 \\
\hline Eng. Sanit. e Gestão Ambiental & $6,25 \%$ & 1 \\
\hline Supervisão e Inspeção escolar & $6,25 \%$ & 1 \\
\hline Tecnologia de alimentos & $6,25 \%$ & 1 \\
\hline Ciências da Natureza & $12,25 \%$ & 2 \\
\hline Nenhuma & $25 \%$ & 4 \\
\hline
\end{tabular}

Fonte: Produção da pesquisadora.

\section{Seção I: Análise dos planos anuais dos professores de Ciências:}

Optou-se posteriormente por delimitar a amostra investigada aos professores do sexto ano, uma vez que o componente de educação ambiental se encontra preconizado na estrutura curricular desse nível. Portanto, após a identificação geral dos professores, procedeu-se à análise exploratória dos planos anuais solicitados aos que atuam no $6^{\circ}$ ano, com o intuito de identificar a presença/ausência de atividades de cunho ambiental. Desse 
modo, compreendeu-se que as atividades e/ou projetos identificados no planejamento e executadas pelos professores configurariam a intenção de inserir a Educação Ambiental nas aulas de Ciências do sexto ano.

Foram disponibilizados 3 planos de um montante de 6 professores do $6^{\circ}$ ano. Os planos analisados receberam o código PL, seguido de um numeral que representa a ordem de análise. Essa investigação justificou-se, pois, a exemplo dos outros conteúdos que compõem o currículo da disciplina Ciências, a inserção da Educação Ambiental também necessita de planejamento, sendo este um momento de reflexão sobre como ocorrerá a ação pedagógica (MANECHINE et al., 2006). É o planejamento que orienta as ações dos professores, bem como os objetivos de aprendizagem a serem alcançados e consequentemente, fomenta as ações de cunho ambiental que farão parte da formação dos alunos. (VASCONCELLOS, 2000).

De acordo com Vasconcellos (2000, p. 33), o plano curricular ou de ensino constitui-se no "referencial com os fundamentos que cada disciplina deve conter, as expectativas de aprendizagem, os conteúdos previstos e as propostas de avaliação para cada ano/série". Ainda segundo o mesmo autor, o planejamento deve promover a articulação entre a ação docente coordenada e organizada, os programas curriculares, a prática da sala de aula e as problemáticas inerentes ao contexto social e cultural onde cada instituição está inserida.

Nesse sentido, ao planejar as atividades de Educação Ambiental, o professor de Ciências terá a oportunidade de levar a problemática socioambiental para a sala de aula de forma articulada, organizada e contextualizada, além de possibilitar mudanças e correções em tempo real, tendo em vista sua flexibilidade. Do conjunto de professores, conseguiu-se três planos anuais, onde os resultados da análise documental estão apresentados no quadro 1.

Quadro 1 - Análise dos planos anuais de ensino dos Professores de Ciências.

\begin{tabular}{|l|l|l|l|}
\hline Plano de ensino & Organização & Conteúdo/unidades & Atividades EA \\
\hline
\end{tabular}




\begin{tabular}{|c|c|c|c|c|}
\hline \multirow{2}{*}{ PL1 } & $\begin{array}{c}\text { Objetivo geral, capaci- } \\
\text { dades, conteúdos, tipos } \\
\text { de situações de ensino } \\
\text { e aprendizagem, instru- } \\
\text { mentos de avaliação }\end{array}$ & $\begin{array}{c}\text { Aquecimento global, efeitos dos } \\
\text { poluentes sobre a saúde, agri- } \\
\text { cultura sustentável, desenvolvi- } \\
\text { mento sustentável, os perigos } \\
\text { da erosão do solo }\end{array}$ & $\begin{array}{c}\text { Não há registro de } \\
\text { atividades de Edu- } \\
\text { cação Ambiental no } \\
\text { plano }\end{array}$ \\
\hline PL2 & $\begin{array}{c}\text { Conteúdo, componentes } \\
\text { curriculares, tipo de ensi- } \\
\text { no aprendizagem, instru- } \\
\text { mentos de avaliação. }\end{array}$ & $\begin{array}{c}\text { Queimadas, agrotóxicos, des- } \\
\text { tino do lixo, o efeito estufa e o } \\
\text { aquecimento global, poluição }\end{array}$ & $\begin{array}{c}\text { Não há registro de } \\
\text { atividades de Edu- } \\
\text { cação Ambiental no } \\
\text { plano }\end{array}$ \\
\hline PL3 & $\begin{array}{c}\text { Unidades temáticas, ob- } \\
\text { jetos de conhecimentos, } \\
\text { habilidades, procedi- } \\
\text { mentos metodológicos, } \\
\text { avaliação: forma e instru- } \\
\text { mentos }\end{array}$ & $\begin{array}{c}\text { Matéria e energia (misturas } \\
\text { homogêneas e heterogêneas), } \\
\text { Vida evolução (Célula como de vida), Terra e univer- } \\
\text { so (Forma e estrutura da Terra. }\end{array}$ & $\begin{array}{c}\text { Não há registro de } \\
\text { atividades de Edu- }\end{array}$ & $\begin{array}{c}\text { cação Ambiental no } \\
\text { plano }\end{array}$ \\
\hline
\end{tabular}

Fonte: Produção da pesquisadora.

O plano de ensino PL1 apresenta um rol de conteúdos bastante extenso relacionado às questões ambientais. O conteúdo planejado é baseado, na sua totalidade, no sumário do livro didático. Há previsão de competências a serem alcançadas, mas não há prenúncio de projetos ou atividades específicas voltadas para a Educação Ambiental. No referido plano, as situações de aprendizagem não são detalhadas, porém são registradas atividades de pesquisa, leitura técnica de jornais e revistas sobre várias temáticas na perspectiva conteudista. Pontua-se que não se identificou atividades que versam sobre o trato ambiental, portanto essas atividades desenvolvidas pelos docentes não são planejadas e nem intencionais.

O plano PL2 tem o conteúdo direcionado para as questões ambientais como por exemplo, queimadas, agrotóxicos, o destino dos resíduos sólidos, poluição. Há dessa forma, um potencial para o desenvolvimento de atividades ou projetos de Educação Ambiental, mas não há registro pontual dessas atividades no plano analisado. As atividades que favorecem o desenvolvimento das capacidades não são detalhadas e referem-se à aula expositiva, trabalho de pesquisa, trabalho em grupo e uso do livro didático. Os conteúdos seguem a sequência do sumário do livro didático adotado. Não há nenhum registro de projeto ou atividades de Educação Ambiental, estas quando ocorrem também não são intencionais ou planejadas. 
No PL3, a organização dos conteúdos já segue as orientações da nova Base Nacional Comum Curricular, isto se explica devido ao fato de que neste ano a escola não adotou livro didático específico. Na maioria das escolas ainda está em vigor as coleções do PNLD para o triênio 2017 a 2019 que trazem o Universo e os ambientes da Terra como conteúdo para o sexto ano. De acordo Base Nacional Comum Curricular, esse conteúdo não é ministrado no sexto ano. A temática e atividades de Educação Ambiental, não estão contempladas nos conteúdos e no plano de ensino. Dentre as habilidades que os estudantes precisam desenvolver está a de "associar a produção de medicamentos e outros materiais sintéticos ao desenvolvimento científico e tecnológico, reconhecendo benefícios e avaliando impactos socioambientais" (BRASIL, 2017). Essa foi a única ocasião em que foi identificada uma referência à temática ambiental. Os procedimentos metodológicos, a exemplo dos outros planos analisados, não estão detalhados. Apesar de ter o registro de impactos ambientais relativos à ciência e tecnologia, os projetos que os professores afirmaram desenvolver não contemplam essa temática. Podemos inferir que estes projetos não são planejados e intencionais, e quando planejados não são executados.

\section{Análise das entrevistas dos professores}

Esta etapa da análise corresponde às concepções dos professores do $6^{\circ}$ ano do Ensino Fundamental sobre a prática da Educação Ambiental nas suas atividades de Ciências. Entrevistou-se seis professores do sexto ano e o diálogo estabelecido foi transcorrido em horários indicados pelos entrevistados, sendo que a média de tempo de todas as entrevistas foi de 50 minutos. Após as entrevistas, procedeu-se a transcrição delas, para posterior exploração minuciosa e análise de conteúdo (BARDIN,2010). No tratamento dos dados obtidos, as unidades de significados foram compiladas por semelhanças de significados, segundo a interpretação dos pesquisadores. Esses dados foram organizados em dois blocos de análise, denominados respectivamente de:

I) Concepções Gerais sobre Educação Ambiental;

II) Perfil de Implementação de EA. 


\section{Bloco I: Concepção Gerais sobre Educação Ambiental}

O bloco I teve a intenção de averiguar e discutir qual a concepção de EA presente no imaginário e na prática docente, e quais contribuições o ensino de Ciências pode trazer para a inserção da Educação Ambiental no âmbito escolar; além de indagar de que forma seus preceitos refletem uma preocupação com a preservação do meio ambiente. Dessa forma, as US das respostas dos professores foram organizadas nas seguintes categorias: a) Definição de EA; b) Contribuições da EA; c) Atitudes Docentes na EA.

Tabela 2 - Descrição das unidades de significado da categoria "Definição de Educação Ambiental"

\begin{tabular}{|c|c|c|c|}
\hline Categoria & Subcategorias & $\begin{array}{l}\text { Freq. } \\
(\%)\end{array}$ & Citação \\
\hline \multirow{4}{*}{ 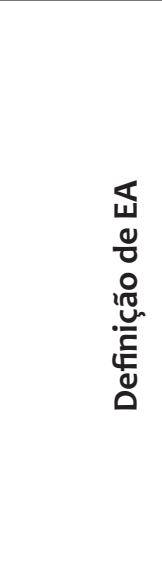 } & Ramo de estudos & 37,5 & $\begin{array}{l}\text { "E o estudo do ambiente e seus } \\
\left.\text { problemas" ( } \mathrm{P}_{3}\right) \\
\left.\text { "É o estudo da natureza" ( } \mathrm{P}_{2}\right)\end{array}$ \\
\hline & Atender o cotidiano & 25 & $\begin{array}{l}\text { "É trazer para os alunos o am- } \\
\text { biente em que ele vive" (P5) }\end{array}$ \\
\hline & Gestão de Recursos Naturais & 18,7 & $\begin{array}{l}\text { "É saber gerir os recursos para } \\
\text { que eles possam sempre ficar dis- } \\
\text { poníveis" }(P 7)\end{array}$ \\
\hline & Conscientização Ambiental & 12,5 & $\begin{array}{l}\text { "É uma forma de tentar cons- } \\
\text { cientizar os alunos e as pessoas" } \\
(P 1)\end{array}$ \\
\hline
\end{tabular}

Fonte: Produção das pesquisadoras.

Em relação à primeira categoria “Definição de EA", os dados revelaram que a maioria dos professores entende que a Educação Ambiental se configura como área de estudos que pode proporcionar o conhecimento do ambiente na perspectiva da resolução de problemas. Para 25\% dos professores pesquisados, a Educação Ambiental proporciona uma proximidade com o cotidiano dos educandos pela possibilidade de trazer para o espaço escolar o ambiente em que ele vive e dessa forma poder nele intervir. Já $18,7 \%$ responderam que a Educação Ambiental significa gestão de recursos naturais, onde os educandos precisam aprender a gerenciar os recursos naturais para que possam estar disponíveis para 
as gerações atuais e futuras, perspectiva que se alinha aos princípios da sustentabilidade. E 12,5\% consideram a Educação Ambiental como sinônimo de conscientização e nessa perspectiva a Educação Ambiental mobiliza todo o seu potencial formador de valores, competências, habilidades e atitudes para a defesa e preservação do meio ambiente.

Pode-se observar, pela análise do conteúdo das entrevistas, a diversidade de visões acerca do que é Educação Ambiental. Na perspectiva de Sato e Carvalho (2005, p. 17):

[...] há uma preocupação comum com o meio ambiente e reconhecimento do papel central da educação para a melhoria da relação com este último, os diferentes autores (pesquisadores, professores, pedagogos, animadores, associações, organismos, etc.) adotam diferentes discursos sobre a EA e propõem diversas maneiras de conceber e praticar a ação educativa neste campo.

Porém, apesar dessa diversidade de entendimentos acerca da EA, sua inserção não depende desse entendimento, assim como não é determinante o momento da escolha do projeto ou atividade de EA, sua incorporação está mais relacionada ao livro didático.

Tabela 3 - Descrição das US da categoria "Contribuições da EA"

\begin{tabular}{|c|c|c|c|}
\hline Categoria & Subcategorias & $\begin{array}{l}\text { Freq. } \\
(\%)\end{array}$ & Citação \\
\hline 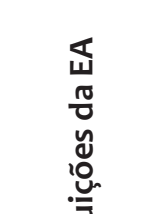 & Formação conceitual & 57,1 & $\begin{array}{l}\text { “Oportunidade de compreender melhor } \\
\text { o ambiente em que vive o aluno" (P4) } \\
\text { "Conteúdos relacionados à realidade do } \\
\text { aluno, questão de sobrevivência" (P3) }\end{array}$ \\
\hline 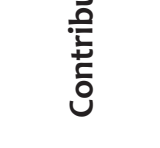 & Formação atitudinal & 42,8 & $\begin{array}{c}\text { "Desperta o interesse pelo cuidado am- } \\
\text { biental" (P1) } \\
\text { "Dá suporte para os alunos" (P6) }\end{array}$ \\
\hline
\end{tabular}

Fonte: Produção das pesquisadoras.

A segunda categoria desse bloco, denominada de "Contribuições da EA", suscitou a formação de duas subcategorias que corresponderam à "Formação Conceitual" e "Formação Atitudinal”. No que diz respeito à "Formação Conceitual” (57,14\% das citações), observou-se que os professores compreendem que a Educação Ambiental, na disciplina de Ciências, contribui com a formação de conhecimento científico, no tocante aos conceitos especializados da ciência na vertente ambiental capacitando os sujeitos em formação, por 
ter correlação direta no seu currículo com os conteúdos científicos sobre o ambiente. Dessa forma, esses conceitos podem favorecer a compreensão dos impactos ambientais das agressões sofridas. As unidades de significado retiradas das entrevistas foram as seguintes: compreensão, conteúdo da realidade do educando e conhecimento.

Em relação à "Formação Atitudinal” (42,8\% das citações), revelou-se que os professores acreditam que o currículo proposto nas Ciências da Natureza pode contribuir nos aspectos de comportamento dos sujeitos em formação, através da aquisição de conhecimento cientifico, dando assim, suporte para os educandos atuarem de forma consciente na interpretação de resolução de questões ambientais que se apresentarem no seu cotidiano, no sentido de cuidar e proteger o meio ambiente. As unidades de significado que compuseram essa subcategoria são as seguintes: cuidado, suporte e prevenção.

Entendeu-se que esses professores, por conseguinte, são conscientes de que a disciplina Ciências reúne em seu currículo assuntos que se constituem importantes ferramentas para a compreensão do ambiente e seus problemas, além de formas de prevenir mais agressões.

Tabela 4 - Descrição das US da categoria “Atitudes Ecológicas”.

\begin{tabular}{|c|c|c|c|}
\hline Categoria & Subcategorias & $\begin{array}{l}\text { Freq. } \\
(\%)\end{array}$ & Citação \\
\hline \multirow{11}{*}{ 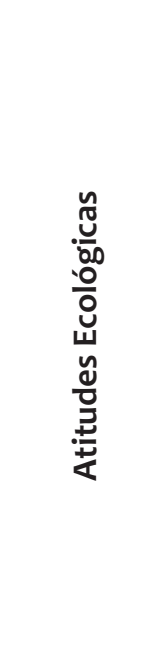 } & \multirow{5}{*}{ Posturas Pessoais } & \multirow{5}{*}{33,34} & "Separo o lixo seco do lixo úmido" (P4) \\
\hline & & & "Ser exemplo com ações cotidianas" (P3) \\
\hline & & & “Reutilizo sacos de supermercado" (P5) \\
\hline & & & $\begin{array}{l}\text { "Oriento o síndico quanto ao reaproveita- } \\
\left.\text { mento da água" ( } \mathrm{P}_{2}\right)\end{array}$ \\
\hline & & & “Denuncio à secretaria” (P1) \\
\hline & \multirow{6}{*}{ Posturas Profissionais } & \multirow{6}{*}{66,66} & $\begin{array}{l}\text { "Oriento, organizo o jardim da escola e pos- } \\
\text { tos de coleta de garrafas PET" (P1) }\end{array}$ \\
\hline & & & "Oriento os alunos sobre pequenas coisas: o \\
\hline & & & perigo da ingestão d e plásticos pelos animais \\
\hline & & & e o descarte de pilhas" (P5) \\
\hline & & & 'Oriento os alunos a confeccionar acessórios \\
\hline & & & e objetos de decoração" (P2) \\
\hline
\end{tabular}

Fonte: Produção das pesquisadoras.

A terceira categoria desse bloco que foi definida como "Atitudes Ecológicas" e revelou duas subcategorias que tratam sobre: posturas pessoais e posturas profissionais. A 
primeira subcategoria denominada de "Posturas Pessoais" teve o intuito de pontuar as ações cotidianas fora do ambiente escolar, dos docentes nos aspectos ambientais e se elas podem influenciar seu trabalho pedagógico de Educação Ambiental. A outra subcategoria elaborada chamada de "Posturas Profissionais", configurada por unidades de significados que se referem à forma como os professores trabalham essas questões em sala de aula, sinalizando projetos e/ou atividades de cunho ambiental que são desenvolvidas no trabalho docente.

Assim, de acordo com a análise do conteúdo das respostas dos professores, três dos sete pesquisados, relataram preocupação com o tratamento dos resíduos sólidos (lixo) e afirmam desenvolver posturas pessoais que se referem ao descarte, separação, coleta e diminuição da produção diária de resíduos. Dois dos professores afirmam reutilizar e reciclar materiais no seu dia a dia, bem como, um docente relatou reaproveitar sacolas de supermercado para que esta não seja descartada de imediato no ambiente. Por fim, um dos docentes afirmou que sua postura pessoal frente aos problemas ambientais no cotidiano e também na escola é de denúncia.

Na perspectiva de Carvalho (2013), a preocupação com a proteção do meio ambiente ainda não está consolidada no cotidiano das pessoas. É necessário que instituições e pessoas tornem-se exemplos para um viver ecologicamente orientado. De acordo com esse pensamento, o exemplo tem caráter formador.

\section{Bloco II: Perfil de Implementação de EA}

O Bloco II teve por objetivo analisar a forma de decisão dos professores de Ciências por implementar as atividades de ensino que se destinam ao viés da Educação Ambiental em suas aulas de Ciências. Os dados coletados que constituíram esse bloco referem-se às unidades de significados mais recorrentes, retiradas dos relatos dos professores sobre a motivação que os levam ao planejamento de suas práticas de EA, relatando principalmente a execução delas. 
Tabela 5 - Descrição detalhada das US da categoria “Motivação para executar”

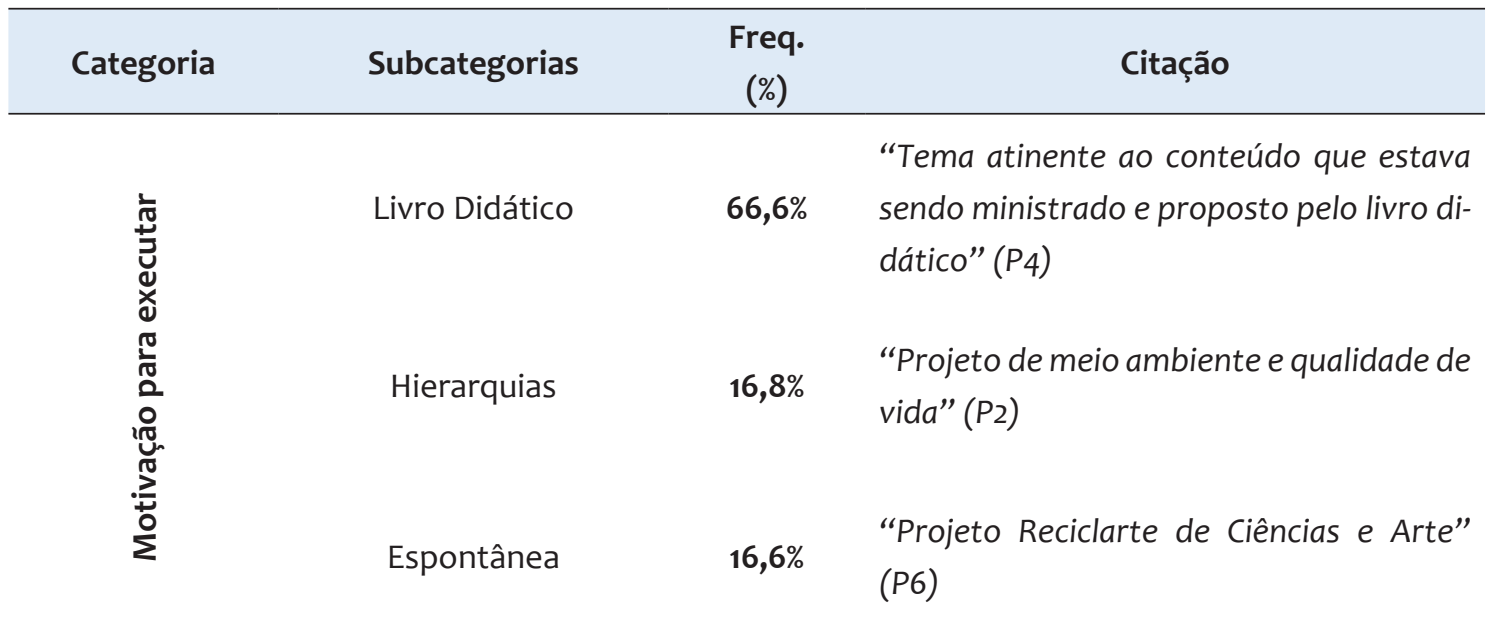

Fonte: Produção das pesquisadoras.

No que concerne à implementação das práticas de EA dos professores designadas ou não em seus planejamentos, os dados revelaram que as unidades mais recorrentes que se encaixaram na categoria "Motivação para executar" fizeram alusão à ação do professor em implementar essas atividades por conta do acompanhamento do Livro Didático (66,6\%). A segunda subcategoria mais representativa diz respeito à realização de atividades de EA obedecendo às hierarquias, ou seja, de atendimento de solicitação e/ou exigência das secretarias de educação ou da gestão escolar. Somente 16,6\% representam as US que implementam as atividades de cunho ambiental de forma espontânea ou intencional, com o objetivo definido de promover a educação ambiental.

No entanto, explica-se que essas atitudes espontâneas visaram a atender alguma circunstância esporádica e não é uma constante na prática pedagógica desses docentes. A exemplo disso, um dos professores relata que temas ambientais são sempre transversais e discutidos nas aulas, mesmo não estando em seu planejamento ou diretamente no assunto trabalhado.

Quanto ao planejamento dos professores, sugeridos por secretarias ou pela gestão escolar, os professores afirmaram que eles acontecem devido a necessidades, como no caso de: conservar as instalações da escola recém-reformada, diminuir o desperdício de lanche após o recreio, diminuir a produção de lixo na escola, ou por alguma ordem do 
governo estadual ou federal que deve ser efetivada no chão da escola. Dessa forma, por vezes, a configuração das atividades já vem delineada, ficando a cargo dos professores as adaptações de conteúdo, seleção de turmas e organização pedagógica do projeto.

Diante do exposto, verificou-se que a inserção da EA ainda apresenta muitas dificuldades e questionamentos no Ensino Fundamental, assim como em todas as modalidades de ensino. A escola é o reflexo da formação recebida pelos professores. Estes compreendem a importância da presença da EA no âmbito escolar, no sentido da formação de cidadãos conscientes de seu papel na defesa de uma sociedade justa e ambientalmente sustentável, mas costumam privilegiar o conteúdo de Ciências desarticulado da Educação Ambiental.

A Política Nacional de Educação Ambiental (BRASIL, 1999) orienta a presença da EA em todas as modalidades e níveis de ensino, tendo como premissa a formação de uma cidadania ambiental local e planetária, no entanto, a formação no ensino superior- sobretudo nos cursos de licenciatura- requer um olhar mais reflexivo e crítico (TOZONI-REIS; CAMPOS, 2014).

\section{CONSIDERAÇÕES FINAIS}

O presente recorte revela resultados que nos permite inferir sobre a prática do professor de Ciências do Sexto Ano, no que se refere à temática ambiental. Os professores afirmaram executar nas suas aulas, atividades e projetos de Educação Ambiental, mas ao analisar os planos anuais verificou-se que esses temas não estão presentes, levando-se a conclusão de que quando são implementadas o fazem de forma espontânea, ou seja, não planejadas, embora o conteúdo programático oficial do nível em questão traga um forte potencial para a inserção da temática ambiental.

A maioria dos professores pesquisados entendem que a Educação Ambiental se configura como um ramo de estudos e, que como tal, deve proporcionar conhecimento sobre o meio ambiente, limitando-se aos aspectos ecológicos. Há uma diversidade de entendimento sobre Educação Ambiental, mas há uma compreensão comum sobre a importância de levar as questões ambientais para os espaços escolares. 
Os docentes entrevistados entendem que a Educação Ambiental no ensino de Ciências contribui para a formação de conceitos relativos à vertente ambiental, capacitando os estudantes a compreenderem as consequências das agressões sofridas pelo meio ambiente na escola e fora dela e como preservá-lo além desse aspecto. Esse conjunto de professores vislumbra que a Educação Ambiental contribui para a ação cidadã ambiental mais consciente, pois fundamenta a resolução de problemas que se apresentam no sentido de cuidar e proteger o meio ambiente.

As posturas profissionais que se referem às atitudes ecológicas desenvolvidas dentro da escola são influenciadas pelas formações cidadãs; logo, verificou-se que de fato as ações pessoais tendem a estimular o trabalho docente, pois o professor desenvolve outro olhar em relação a questão ambiental que extrapola os aspectos meramente didáticos.

Outro aspecto analisado foi o perfil de implementação da Educação Ambiental que tem no livro didático a motivação para executar as atividades de Educação Ambiental. Compreende-se a influência do livro didático pelo fato de ser em algumas situações escolares, o único ou principal instrumento de conhecimento tanto do professor quanto dos estudantes, mas as atividades de cunho ambiental podem se apresentar nas escolas por determinação das secretarias de educação ou de forma espontânea, sem planejamento esse aspecto nos direciona a perceber a dificuldade de inserção da educação ambiental nas escolas, pois a mesma não se constitui uma intenção de formar cidadãos ecológicos na perspectiva de mudança atitudinal, pode-se dizer então que o trabalho em desenvolver cidadania ecológica tem a duração de um projeto ou data comemorativa.

Para a inserção da Educação Ambiental nas escolas e a consequente formação de cidadãos ecológicos não basta a formação inicial e continuada do professor, nem ter atividades contempladas nos livros didáticos, mas é necessário que o professor traga dentro de si os valores, atitudes e comportamento na direção da Educação Ambiental, para que ele possa ser o modelo que irá inspirar o comportamento dos estudantes e da comunidade escolar como um todo.

É importante ressaltar que não cabe apenas ao professor a tarefa de inserir a Educação Ambiental nas escolas, bastaria cumprir o que rege a Política Nacional de 
Educação Ambiental (PNEA) que prevê que a Educação Ambiental deve estar presente de forma articulada em todos os níveis e modalidades de ensino. Cabe também refletir e investigar a presença da educação ambiental nos cursos de formação de docentes e em especial do professor de Ciências, no intuito de verificar se os mesmos adquirem conhecimentos relativos à temática ambiental.

Outro aspecto que deve ser alvo das reflexões e análises sobre a inserção da Educação Ambiental é a sua quase ausência verificada na Base Nacional Comum Curricular (BNCC). A temática ambiental deveria ser preocupação de todas as áreas do conhecimento e com a sua ausência no currículo de Ciências essa dificuldade de inserção da Educação Ambiental tende a se acentuar, o que torna a ameaça à sobrevivência do planeta ainda mais grave tendo em vista o recrudescimento dos problemas ambientais no atual cenário.

\section{REFERÊNCIAS}

BARDIN, Laurence. Análise de conteúdo. São Paulo: Loyola, 2010.

BOGDDAN, Robert C.; BIKLEN, Sari Knopp. Investigação qualitativa em educação: uma introdução à teoria e aos métodos. 12. ed. Porto: Porto Editora, 1994.

BRASIL. Ministério da Educação. Secretaria de Educação Fundamental. Parâmetros Curriculares Nacionais: Ciências Naturais. Brasília: MEC, 1997.

BRASIL. Casa Civil. Lei nº 9.795, de 27 de abril de 1999. Dispõe sobre a educação ambiental, institui a Política Nacional de Educação Ambiental e dá outras providências. Brasília: Casa Civil 1999. Disponível em: http://www.planalto.gov.br/ccivil_03/leis/l9795.htm. Acesso em: 18 de jul. de 2019.

BRASIL. Ministério da Educação. Secretaria de Educação Básica. Base Nacional Comum Curricular: Ensino Fundamental. Brasília: MEC, 2017.

CARVALHO, Isabel Cristina de Moura. Educação ambiental: a formação do sujeito ecológico. 6. ed. São Paulo: Cortez, 2012.

CARVALHO, Isabel Cristina de Moura. O sujeito ecológico: a formação de novas identidades na escola. In: PERNAMBUCO, Marta; PAIVA, Irene. (Orgs.). Práticas coletivas na escola. 1. ed. Campinas: Mercado de Letras, 2013. v. 1, p. 115-124.

CORBIN, Juliet; STRAUSS, Anselm. Basics of Qualitative Research: Techniques and Procedures for Developing Grounded Theory. 3. ed. Thousand Oaks: Sage, 2008.

DIAS, Genebaldo Freire. Educação Ambiental: princípios e práticas. Saraiva, São Paulo, 
FEITOSA, Danilo da Silva. Do bucólico Cutim ao Bairro Anil. 2016. 57 f. Monografia (Licenciatura em História) - Departamento de História e Geografia, Universidade Estadual do Maranhão, São Luís, 2016.

IZQUIERDO, Mercê; SANMARTÍ, Neus; ESPINET, Mariona. Fundamentación y diseño de las prácticas escolares de ciencias experimentales. Enseñanza de las Ciencias, v. 17, n. 1, p. 4560, 1999.

LIMA, Gustavo Ferreira da Costa. Educação ambiental crítica: do socioambientalismo às sociedades sustentáveis. Educação e Pesquisa, São Paulo, v.35, n.1, p. 145-163, jan./abr. 2009.

LÜDKE, Menga; ANDRÉ, Marli E. D. A. Pesquisa em educação: abordagens qualitativas. São Paulo: E.P.U. 1986.

KRASILCHICK, Myriam; MARANDINO, Martha. 0 ensino de ciências e cidadania. 2. ed. São Paulo: Moderna, 2007.

MANECHINE, Selma Rosana Santiago et al. A inserção de conceitos científicos no cotidiano escolar. Ensaio Pesquisa em Educação em Ciências. Belo Horizonte, v.8, n.1, p.55-68, 2006.

MARQUES, Clara Virgínia Vieira Carvalho Oliveira. "Perfil dos cursos de formação dos programas de licenciatura em química das instituições públicas do ensino superior da região nordeste do país". 2010. 291 f. Tese (Doutorado em Química) - Programa de Pós-graduação em Química, Universidade Federal de São Carlos, São Carlos, 2010.

MINAYO, Maria Cecília de Souza (Org.). Pesquisa social: teoria, método e criatividade. 29. ed. Petrópolis: Vozes, 2010.

PASI, Elizabeth Bozoti, BOZELLI, Reinaldo Luiz. Sentidos de educação ambiental mobilizados em discursos de professores de escolas envolvidos na formação de licenciandos em ciências biológicas. Investigações em Ensino de Ciências - V22 (2), pp. 33-56, 2017.

RAMOS, Elisabeth Christmann. Educação ambiental: origem e perspectivas. Educar, Curitiba, n.18, p.201-218. 2001.

SATO, Michele; CARVALHO, Isabel Cristina de Moura. Educação ambiental: pesquisa e desafios. 1. reimp. Artmed: Porto Alegre, 2005.

SENA, Lívia Moreiras. BONOTTO, Dalva Maria Bianchini. A dimensão valorativa da temática ambiental e o trabalho com valores em aulas de ciências. Nuances: estudos sobre Educação. Ano XVIII, v. 23, n. 24, p. 179-199, set./dez. 2012.

SILVA, Odair Vieira da. Sistemas produtivos, desenvolvimento econômico e degradação ambiental. Revista Científica Eletrônica De Turismo, Garça, n.6, jan., 2007

TOZONI-REIS, Marília Freitas de Campos; CAMPOS, Luciana Maria Lunardi. Educação ambiental escolar, formação humana e formação de professores: articulações necessárias. 
Educar em Revista, Curitiba, n. 3, p. 145-162, 2014.

VASCONCELLOS, Celso dos S. Planejamento: Projeto de Ensino-Aprendizagem e Projeto Político-Pedagógico. 7. ed. São Paulo: Libertat, 2000.

Recebido em: 30/09/2019

Parecer em: 06/11/2019

Aprovado em: 08/11/2019 